\title{
Model Perlindungan dan Pengelolaan Lingkungan Hidup dalam Mewujudan Good Governance
}

\author{
Agung Budi Prastyo ${ }^{1}$, Rodhi Agung Saputra ${ }^{2 *}$, Dauri ${ }^{3}$, Ricco Andreas ${ }^{4}$ \\ 1, 2, 3, ${ }^{4}$ Fakultas Hukum Universitas Lampung, Bandar Lampung, Indonesia \\ *E-mail: rodhiagungsaputra@gmail.com
}

Dikirim: 29/10/2020

\begin{tabular}{l}
\hline Info Artikel \\
Keywords: \\
Model; Environment; \\
Good Governance. \\
\\
Kata Kunci: \\
Model; Lingkungan \\
Hidup; \\
Governance.
\end{tabular}

Direvisi: 20/03/2021

Dipublikasi: 25/3/2021

Abstract of authority related to environmental management in Way Kanan Regency and to find a model of good environmental supervision and management in the district by the Environment Agency in realizing good governance. The method used in this study is a normative-empirical research method using a statute approach and in-depth interviews. The findings of this study are that the implementation of the authority of the environmental services in the regions is not optimal so that environmental damage occurs and the model of environmental protection and management, waste and waste that uses the principles of good governance is optimal. It is hoped that future regulations related to the authority of the environmental services in the regions must have broad powers, covering aspects of planning, implementation, supervision and law enforcement. Its duties and functions must integrate the coordination and operational functions, and there is a clear arrangement of relations between institutions related to environmental management.

Abstrak
Penelitian ini merupakan penelitian yang bertujuan untuk mengetahui dan
mengkaji penerapan kewenangan terkait pengelolaan lingkungan hidup di
Kabupaten Way Kanan dan menemukanmodel pengawasan dan
pengelolaan lingkungan yang baik di daerah kabupaten oleh Dinas
Lingkugan Hidup dalam mewujudkan good governance. Metode yang
digunakan dalam penelitian ini adalah metode penelitian normatif-empiris
dengan menggunakan pendekatan statute approach dan in-depth
interviews. Temuan penelitian ini adalah pelaksanaan kewewenang dinas
lingkungan di daerah yang kurang optimal sehingga terjadinya kerusakan
lingkungan dan model perlindungan dan pengelolaan lingkungan hidup,
sampah dan limbah yang menggunakan prinsip-prinsip good governance
sudah cukup optimal. Harapan pengaturan ke depan terkait kewenangan
dinas lingkungan hidup di daerah harus memiliki kewenangan yang luas,
yang meliputi aspek perencanaan, pelaksanaan, pengawasan,dan penegakan
hukum. Tugas dan fungsinya harus mengintegrasikan fungsi koordinasi dan
fungsi operasional, dan ada tata hubungan yang jelas antar lembaga yang
berhubungan tentang pengelolaan lingkungan hidup.

DOI:

10.47268/sasi.v27i1.419 


\section{A. PENDAHULUAN}

Permasalahan lingkungan hidup yang disebabkan oleh sampah dan limbah seperti sekarang ini tidak hanya menjadi permasalahan utama di daerah perkotaan, melainkan di daerah-daerah kabupaten khususnya Kabupaten Way Kanan. Pertumbuhan penduduk yang meningkat, adalah alasan yang paling berpengaruh atas terjadinya perubahan kualitas lingkungan hidupyang kurang baik dan tidak sehat. ${ }^{1}$ Konsekuensi dari pertumbuhan penduduk khususnya di way kanan adalah meningkatnya kebutuhan lahan atau tanah (pemukiman), air bersih dan timbulnya permasalahan diantaranya masalah sosial dan meningkatnya masalah kriminalitas serta berubahnya tatanan lingkungan. ${ }^{2}$ Pencemaran lingkungan dapat mengakbatkan rusaknya ekosistem lingkunga. ${ }^{3}$ Sedangkan Lingkungan hidup yang baik dan sehat merupakan hak asasi setiap warga negara Indonesia sebagaimana diamanatkan dalam Pasal 28H Undang-Undang Dasar Negara Republik Indonesia Tahun 1945 yang berbunyi, Setiap orang berhak hidup sejahtera lahir dan batin bertempat tinggal dan mendapatkan lingkungan hidup yang baik dan sehat serta berhak memperoleh pelayanan kesehatan.

Menjalankan apa yang telah diamanatkan dalam Undang-Undang Dasar Negara Republik Indonesia Tahun 1945 tersebut.Lingkungan daerah perkotaan dan pedesaan memang berbeda. Daerah perkotaan yang lebih berpotensi terjadi permukiman kumuh karena lahan yang semakin terbatas, dan mahal. ${ }^{4}$ Hal ini yang menyebabkan perlunya pelaksanaan kewenangan dinas lingkunga hidup dalam melaksanakan pengelolaan lingkungan hidup secara optimal. Era otonomi daerah seperti sekarang ini berakibat terhadap perubahan berbagai aturan dan kebijakan yang terkait pengelolaan lingkungan hidup. Berbagai urusan lingkungan yang semula cenderung sentralistik, oleh karena itu perlu dilaksanakan secara maksimal oleh dinas lingkungan hidup, meskipun ada semacam resentralisasi kewenangan melalui Undang-undang Nomor 23 Tahun 2014 tentang Pemerintahan Daerah. ${ }^{5}$

Keadaaan lingkungan hidup di daerah khususnya di way kanan yang banyak terdapat pencemaran lingkungan akibat sampah dan limbah, hal ini menunjukkan belum optimalnya peran dinas lingkungan hidup dalam melaksanakan tugasnya. Salah satu hal yang menjadi kendala mengenai penerapan dan penegakan hukum dalam pengelolaan lingkungan terutama dalam penerapan sanksinya. Sanksi-sanksi yang terdapat dalam peraturan terutama yang menyangkut pencemaran lingkungan tidak memberikan efek jera bagi masyarakat. Selain itu peran dinas lingkungan hidup sangat penting dalam mengeluarkan kebijakan terhadap pengelolaan lingkungan. Apabila pemerintah mampu melaksanakan kewenangannya ${ }^{6}$ dan prinsip-prinsip yang dikembangkan dalam Good Governance ${ }^{7}$ seperti partisipasi pemerintah, lembaga terkait, masyarakat, aturan hukum (rule of law), dan trasparansi dalam pelaksanaan kewenangan pengelolaan lingkungan hidup akan tetapi faktanya pelaksanaan kewenangan oleh dinas lingkungan hidup belum dilaksanakan secara optimal yang dapat dilihat banyaknya lingkungan hidup yang kurang baik dan kumuh akibat limbah dan sampah.

${ }^{1}$ Rasyid, W., \& Hidayat, A. (2019), Penegakan Hukum Lingkungan Dalam Bidang Pengelolaan Sampah Sebagai Perwujudan Prinsip Good Environmental Governance di Kota Parepare. Madani Legal Review, 3 (2), 135 153. https://doi.org/10.31850/malrev.v3i2.407, h. 136.

2 Waas, R. V. (2014). Perlindungan Hukum Terhadap Hak Atas Lingkungan Hidup Ditinjau Dari Perspektif

Hukum Internasional Dan Hukum Nasional Indonesia. SASI, $20 \quad$ (1), 84-93. https://doi.org/10.47268/sasi.v20i1.348, h 81.

${ }^{3}$ Rahmadi, Takdir. (2011), Hukum Lingkungan di Indonesia, Jakarta: Raja Grafindo Persada, h. 3.

${ }^{4}$ Ragil, Agus Priyanto. (2011). Partisipasi Masyarakat Dalam Pengelolaan Sampah Di Kelurahan Jombang Kota Semarang(Analisis Sosio Yuridis Pasal 28 Undang Undang No 18 Tahun 2008 Tentang Pengelolaan Sampah) Skripsi: Universitas Negeri Semarang, h.2.

${ }^{5}$ Akib, M. (2012). Wewenang Kelembagaan Pengelolaan Lingkungan Hidup di Era Otonomi Daerah, Jurnal. Media Hukum, 19 (2), 239-250. https://journal.umy.ac.id/index.php/jmh/article/view/103, h. 242.

${ }^{6}$ Syafri, Wirman. (2011), .Dynamic Governance dan Prespektif Penyelenggaraan Pemerintah Daerah. Diakses pada www.ipdn.ac.id

${ }^{7}$ Perdana, Gema. (2019), Menjaga Netralitas ASN dari Politisasi Birokrasi. Negara Hukum: Membangun Hukum untuk Keadilan dan Kesejahteraan, 10 (1), 109-128. https://doi.org/10.22212/jnh.v10i1.1177, h. 111. 
Berdasarkan uraian latar belakang diatas, maka yang menjadi permasalahan dalam penelitian ini adalah bagaimanakah pelaksanaan kewenangan Dinas Lingkungan Hidup dalam mengelola lingkungan hidup sebagai perwujudan Prinsip Good Governance.di Kabupaten Way Kanan dan bagaimanakah model penerapan prinsip-prinsip good governance dalam perlindungan dan pengelolaan lingkungan hidup di Kabupaten Way Kanan.

\section{B. METODE PENELITIAN}

Metode penelitian yang digunakan adalah metode penelitian normatif, dengan menggunakan pendekatan statute approach dan pendekatan in-depth interviews terkait pelaksanaan kewenanngan pengelolaan lingkungan hidup kepada pihak yang bertanggung jawab atas lingkungan hidup di Kabupaten Way Kanan. ${ }^{8}$ Pendekatan statute approach yaitu mengkaji hal-hal yang menyangkut asas-asas hukum, pandangan dan doktrin-doktrin hukum, dan peraturan perundang undangan terkait lingkungan hidup, ${ }^{9}$ dan data yang akurat serta dapat dipertanggung jawabkan kebenaranya. ${ }^{10}$ Pendekatan in-depth interviews terkait pelaksanaan kewenangan dinas lingkungan hidup dalam mengelola lingkungan hidup di Kabupaten Way Kanan. ${ }^{11}$ Selain itu juga diadakan pemeriksaan mendalam terhadap fakta hukum tersebut untuk kemudian mengusahakan pemecahan atas permasalahan yang timbul didalam gejala yang bersangkutan. ${ }^{12}$.

\section{PEMBAHASAN}

\section{Pelaksanaan Kewenangan Dinas Lingkungan Hidup Dalam Mengelola Lingkungan Hidup Sebagai Perwujudan Good Governance Di Kabupaten Way Kanan}

Pengaturan terkait wewenang dalam melakukan perlindungan dan pengelolaan lingkungan hidup, bersumber dari dalamUndang-Undang Nomor 32 Tahun 2009 terntang Perlindungan dan Pengelolaan Lingkungan Hidup (UU PPLH) Pasal 1 ayat (2), diantaranya adalah upaya sistematis dan terpadu yang dilakukan untuk melestarikan fungsi lingkungan hidup dan mencegah terjadinya pencemaran dan kerusakan lingkungan hidup yang meliputi perencanaan, pemanfaatan, pengendalian, pemeliharaan, pengawasan, dan penegakan hukum. ${ }^{13}$ Terkait hal ini, kerusakan lingkungan akibat limbah dan sampah yang terjadi di Kabupaten Way Kanan termasuk dalam permasalahan yang harus diselesaikan karena jika tidak segera diselesaikan menyebabkan dampak yang lebih parah lagi serta isi dari Pasal 1 ayat (2) diatas tidak akan tercapai terkait untuk melestarikan lingkungan hidup. Melalui UU PPLH, pemerintah memberi kewenangan yang sangat luas kepada pemerintah daerah dalam melakukan perlindungan dan pengelolaan lingkungan hidup di daerah masing-masing karena Penyelenggaraan pemerintahan yang baik akan mempengaruhi dan menentukan pengelolaan lingkungan hidup yang baik. ${ }^{14}$

\footnotetext{
8 Marzuki, Peter Mahmud. (2011), Penelitian Hukum, Jakarta: Kencana Prenada Media Group, h 352.

9 Pinilih, S. A. G. (2015). Pelaksanaan Tugas dan Wewenang Badan Lingkungan Hidup Kota Semarang Dalam Penegakan Hukum Di Bidang Lingkungan. Notarius: Jurnal Studi Kenotariatan, 8, (2), 236251. https://doi.org/10.14710/nts.v8i2.10262 h.238.

10 Fajar, Mukti., \& Achmad,Yulianto. (2010), Dualisme Penelitian Hukum Normatif \& Empiris, Yogyakarta: Pustaka Pelajar, h. 34.

11 Marzuki, Peter Mahmud. Op. Cit.

12 Muhammad, Abdulkadir. (2004), Hukum dan penelitian Hukum, Bandung: Citra Aditya Bakti, h. 32.

13 Saija, V. J. E. (2014). Wewenang Pemerintah Daerah Dalam Pemberian Izin Lingkungan Hidup. SASI, 20 (1), 71-83. https://doi.org/10.47268/sasi.v20i1.347, h. 68.

14 Nopyandri. (2011), Penerapan Prinsip Good Environmental Governance dalam Perda Kabupaten Sleman Provinsi Daerah Istimewa Yogyakarta. Jurnal Ilmu Hukum, 2, (1), 31-48. https://onlinejournal.unja.ac.id/JSSH/article/view/52, h 35.
}

$$
\text { 86|SASI Vol. } 27 \text { No.1, Januari- Maret } 2021
$$


Pelaksanaan kewenangan terkait pengelolaan lingkungan hidup secara optimal akan berpengaruh pada keberhasilan pengelolaan lingkungan dan sumber daya alam agar dapat memberi manfaat yang optimal, baik untuk generasi sekarang maupun generasi mendatang. Sesuai dengan Pasal 12 ayat (2) UU NO. 23 Tahun 2014 tentang Pemerintah Daerah yang menyatakan urusan pemerintahan daerah wajib diantaranya adalah mengatur dan mengelola lingkungan hidup dan Pasal 63 ayat (1) dan UU NO. 32 tahun 2009 tentang Perlindungan dan Pengelolaan Lingkungan Hidup (UU PPLH) yang pada intinya menyatakan terkait tugas dan wewenang pemerintah daerah dalam melaksanakan perlindungan dan pengelolaan lingkunga hidup yang diantaranya adalah menetapkan kebijakan, menetapkan norma dan SOP. Oleh karena itu, keberadaan kelembagaan pengelolaan lingkungan baik di pusat maupun di daerah memiliki peran penting dalam melakukan pengelolaan lingkungan hidup. ${ }^{15}$ Oleh karena itu, pelaksanaan kewenangan pengelolaan lingkungan secara optimal baik di pusat maupun di daerah sangat berpengaruh atas keadan lingkungan hidup yang ada.

Berdasarkan Pasal 71 ayat (2) UU PPLH yaitu Menteri, gubernur, atau bupati/walikota dapat mendelegasikan kewenangannya dalam melakukan pengawasan kepada pejabat/instansi teknis yang bertanggung jawab di bidang perlindungan dan pengelolaan lingkungan hidup. Artinya Dinas Lingkungan Hidup memiliki kewenangan yang cukup untuk, melakukan pemantauan konsi lingkungan hidup yang ada di daerahnya. Berdasarkan aturan ini, Dinas Lingkungan Hidup khususnya DLH Way Kanan tidak dapat beralasan jika terjadinya pencemaran atau kerusakan lingkungan disebabkan kurangnya kewenangan yang diberikan baik dari pusat maupun daerah. Pelaksanaan kewenangan DLH meliputi pengawasan terhadap lingkungan hidup yaitu upaya yang meliputi pemantauan penaatan persyaratan, ketentuan teknis dan administrasi oleh pemerintah daerah, (Dinas Lingkungan Hidup) kepada masyarakat yang melakukan kegiatan usaha di Kabupaten Way Kanan yang memiliki limbah atau sampah. Kehadiran perusahaan di lingkungan masyarakat ${ }^{16}$ yang dapat menimbulkan kerusakan lingkungan akibat limbah dan sampah. Adanya perusahaan yang dibangun nyatanya tidak hanya memberikan keuntungan semata, akan tetapi juga menimbulkan permasalahan. ${ }^{17}$

Tercemarnya lingkungan hidup yang disebabkan oleh limbah dan sampah baik dari perusahaan, pengusaha, dan masyarakat mengakibatkan nilai estetika dari lingkungan tersebut akan menurun, lingkungan yang tercemar tersebut akan terlihat kumuh. Jika hal ini terus dibiarkan dan tidak ada implementasi secara optimal hal ini akan mengganggu sistem alami dari lingkungan dan rusaknya ekosistem serta komponen yang terdapat pada lingkungan tersebut.

Pelaksanaan kewenangan DLH terkait pengelolaan lingkungan hidup jika dirasa faktor penghambatnya adala sarana dan prasarana terutama jarak, maka DLH dapat bersinergi dengan perangkata pemerintahan kecamatan sesuai dengan Undang-Undang Nomor 23 Tahun 2014 Tentang Pemerintahan Daerah pada pasal 209 ayat (2) huruf f yang menjelaskan bahwa Kecamatan adalah perangkat daerah Kabupaten/Kota. Lebih lanjut, pada pasal 221 ayat (1) secara tegas menjelaskan bahwa Kecamatan dibentuk dalam rangka meningkatkan koordinasi penyelenggaraan pemerintahan. Artinya dengan adanya pemerintah Kecamatan dan Camat sebagai pimpinan tertinggi di Kecamatan harus dapat mengkoordinasikan semua urusan pemerintahan di Kecamatan, kemudian juga Camat harus memberikan pelayanan publik dan pemberdayaan masyarakat desa atau kampong untuk ikut seta dalam perlindungan dan pengelolaan lingkungan hidup. ${ }^{18}$

15 Akib, M. Op. Cit, h. 242

16 Hidayat, Arief., \& Samekto, FX Adjie. (2007), Penegakan Hukum Lingkungan di Era Otonomi Daerah, Yogyakarta, Badan Penerbit Universitas Diponegoro, h. 30-31

17 Pinilih, S. A. G. Op. Cit. h. 242.

18 Muis, Muhammad Amirul Haq., Saleh, Hasrat Arief., Rusli, Andi M., (2014), Analisis Implementasi Good Governance dalam Pelayanan Publik di Kecamatan Panakukkang Kota Makassar, Government: Jurnal Ilmu Pemerintahan, 7 (2), 73-82. https://journal.unhas.ac.id/index.php/government/article/view/1246. h. 74.

$$
\text { 87 |S A S I Vol. } 27 \text { No.1, Januari - Maret } 2021
$$


Dengan demikian, kunci utama keberhasilan penyelengaraan Good Governance (pemerintahan yang baik) terkait pelaksanaan kewenangan pengelolaan lingkungan hidup itu berada pada lembaga itu sendiri dan partisipasi khususnya dalam hal lingkungan hidup. Wasistiono (2003: 28) mengemukakan bahwa tuntutan adanya good governance ini timbul karena adanya penyimpangan dalam penyelenggaraan demokratisasi sehingga mendorong kesadaran warga negara untuk menciptakan sistem atau paradigma baru untuk mengawasi jalannya pemerintahan agar tidak melenceng dari tujuan semula. Selanjutnya, Purnomowati dan Ismini (2014: 68) juga menambahkan bahwa upaya mengikutsertakan masyarakat (stakeholders) dalam pelaksanaan pembangunan hanya dapat terwujud bila kehidupan demokrasi berjalan dengan baik. Proses demokratisasi akan berjalan dengan baik jika tercipta supremasi hukum yang didukung oleh good governance. Oleh karena itu good governance merupakan paradigma baru dalam penyelenggaraan pemerintahan yang didalamnya melibatkan kolaborasi antara pemerintah dengan swasta dan masyarakat. Perubahan tersebut lebih dikenal dengan pergeseran paradigma dari pemerintahan (goverment) menjadi tata pemerintahan (governance) sebagai wujud dari interaksi sosial politik antara pemerintahan dengan masyarakat.

Goodgovernance dalam kontek pengelolaan lingkungan hidup adalah dengan bersinerginya antara pemerintah baik pusat maupun daerah. G.H Addink mengatakan bahwa konsep good governance dalam konteks pemerintahan adalah dalam rangka interaksi suatu Pemerintah dan bangsanya. Good Governance merepresentasikan beberapa hal, diantaranya adalah hak-hak, fundamental, efektifitas dan transparansi, akuntabilitas Pemerintah (dalam hal masalah pengelolaan lingkungan hidup), dan pengembangan aturan hukum (rule of law). Government adalah salah satu pihak dalam governance. pihak lain yang terlibat dalam governance dalam perumusan atau pembahasan terkait pengelolaan lingkungan hidup dituntut adanya sinergi di antara ke tiga pihak yang ada yaitu Pemerintah itu sendiri, masyarakat, dan pihak swasta.

Pelaksanaan kewenangan DLH secara ptimal terkait pengelolaan lingkungan hidup dapat ditekankan pada bagian pengawsan lingkungan hidup baik secara preventif dan represif. Menurut Feriose Rizal Seksi Perencanaan dan Kajian Dampak Lingkungan pengawasan dari Dinas Lingkungan Hidup ${ }^{19}$ terkait pengawasan lingkuan hidup di Kabupaten Way Kanan.

"Pengawasan terhadap lingkungsn hidup sudah dilakukan secara maksimal di tiap-tiap kecamatan, akan tetapi DLH membutuhkan bantuan baik pemerintahan kecamatandan desa serta masyarakat untuk turut membantu pengawsan lingkungan hidup agar tidak rusak"

Hal ini sesuai dengan Undang-Undang Nomor 23 Tahun 2014 Tentang Pemerintahan Daerah pada pasal 209 ayat (2) huruf f yang menjelaskan bahwa Kecamatan adalah perangkat daerah Kabupaten/Kota. Lebih lanjut, pada pasal 221 ayat (1) secara tegas menjelaskan bahwa Kecamatan dibentuk dalam rangka meningkatkan koordinasi penyelenggaraan pemerintahan dan Undang-Undang Nomor 32 Tahun 2009 Tentang PPLH pada pasal Pasal 70 UU PPLH. Peran serta masyarakat dalam pengawasan pembuangan limbah karet oleh pelaku pengusaha karet ini dapat berupa pengawasan sosial, seperti pemberian usul, pendapat, saran, keberatan serta pengaduan (penyampaian informasi atau laporan) terkait pencemaran lingkungan akibat limbah karet. Hal ini bertujuan untuk meningkatkan kepedulian dalam perlindungan dan pengelolaan lingkungan hidup, menumbuhkembangkan kemampuan dan kepeloporan masyarakat.

\section{Model Perlindungan Dan Pengelolaan Lingkungan Hidup, Limbah Dan Sampah Dalam Mewujudkan Good Governance Di Kabupaten Way Kanan}

Penerapan prinsip-prinsip good government harus di terapkan dalam pemerintahan

19 Data hasil wawancara study lapangan Perencanaan dan Kajian dampak Lingkungan, Feriose Rizal 88|SASI Vo1. 27 No.1, Januari- Maret 2021 
khususnya dalam bidang perlindungan dan pengelolaan lingkungan hidup karena hal ini merupakan aspek penting dalam kehidupan sehari-hari. Good government diawali dari lingkungan Perserikatan Bangsa-Bangsa (PBB), yang awal mulanya dari Organization for The economic Cooperation and Development (OECD). Carolina dalam Good Governance Civil Society and Democracy. ${ }^{20}$ Didalamnya dijelaskan substansi-substansi penting dalam good governance diantaranya adalah sebagai berikut :

a) human rights observance and democracy,

b) market reforms,

c) bureaucratic reform (corruption and transparency),

d) environmental protection and sustainable development, dan

e) reduction in military and defence expenditures and non production of weapons of massdestruction. Dari dua kelompok komponen good governance (OECD dan UNDP).

Pelaksanaan kewenangan DLH terkait perlindungan dan pengelolaan lingkungan hidup termasuk dalam pelayanan publik yang menjadi hak masyarakat di daerahnya. Dalam melaukan pelayanan publik haruslah selalu memperhatikan asas-asas umum pemerintahan yang baik sebagai perwujudan good governance, agar masyarakat merasa baha jalanya pemerintahan didasarkan pada kehendak masyarakat dan tidak sepihak saja. ${ }^{21}$

Pelaksanaan Kewenangan terkait perlindungan dan pengelolaan lingkungan hidup oleh DLH di kabupaten Way Kanan lebih ditekankan pada pengawasan dan perizinan lingkungan baik secara preventif dan represif yang menerapkan konsep dan prinsip-prinsip good governance mulai diterapkan. Hal ini dijelaskan oleh Sutriono Bidang Pengendalian Pencemaran dan Kerusakan Lingkungan DLH way kanan.

"Pengawasan terhadap lingkungan hidup misalnya pencemaran lingkungan akibat limbah dan sampah dilaksanakan secara preventif dan represif sesuai Undang-Undang yang berlaku. Akan tetapi penindakanyan tidak dapat langsung dilakukan, melainkan harus melalui beberapa tahapan terkecuali ada aduan dari masyarakat terkait pencemaran lingkungan yang disebabkan oleh limbah dan sampah."

Sesuai pasal 74 UU PPLH, Dinas Lingkungan Hidup selaku pejabat pengawas berwenang melakukan penindakan terhadap pelaku pencemaran lingkungan dan memiliki kewenangan melakukan pengawasan secara preventif dan represif di lingkungan daerahnya. Pelaksanaan pengawasan oleh Dinas Lingkungan Hidup Kabupaten Way Kanan terhadap limbah karet harus segera dilaksanakan. Hal ini merupakan upaya konkret yang harus dilakukan, dikarenakan sudah banyak perubahan yang terjadi pada lingkungan hidup akibat limbah karet. Adapun bentuk upaya pengawasan terhadap pembuangan limbah karet terkait perusahaan dan pengusaha karet karet di Kabupaten Way Kanan dinas lingkungan hidup menyediakan instrumen-instrunen pengawasan baik secara preventif dan represif.

Pengawasan preventif yang dilakukan Dinas Lingkungan Hidup terkait perlindungan dan pengawsan lingkugan hidup adalah dengan diadakannya instrumen perizinan (izin pendirian usaha dan izin lingkungan), melakukan sosialisasi dan arahan kepada seluruh masyarakat khususnya masyarakat yang melakukan kegiatan usaha,dan melakukan pembinaan mengenai pentinganya menjaga lingkungan hidup kepada masyarakat, memberitahukan tata cara pengolahan limbah dan sampah. Misalnya pengawasan preventif yang dilakukan terhadap limbah dan sampah adalah diwajibkanya AMDAL atau UKL-UPL, adanya Izin lingkungan dan izin pembuangan limbah yang harus dimiliki oleh perusahaan atau pengusaha serta seluruh

${ }^{20}$ Hadjon, Philipus M. (2002 Good Governance dalam Penyelenggaraan Pemerintahan Daerah, Meritokrasi, 1, (1), h. 9.

21 Arisaputra, Muhammad Ilham. (2013), Penerapan Prinsip-Prinsip Good Governance Dalam Penyelenggaraan Reforma Agraria Di Indonesia. Yuridika, $28 \quad$ (2), 188-216. http://dx.doi.org/10.20473/ydk.v28i2.1881. h. 191.

89|SASI Vo1. 27 No.1, Januari- Maret 2021 
masyarakat. Hal tersebut bertujuan agar DLH dapat melakukan pengawasan secara terpadu terhadap kondisi lingkungan hidup yang ada diwilayah kewenangannya.

Pengawasan represif merupakan upaya yang dilakukan DLH untuk mendisiplinkan masyarakat yang melakukan pencemaran dan kerusakan lingkungan akibat tidak memperhatiakan atau melanggar aturan yang sudah ditentukan dalam melakukan pembuangan limbah khususnya limbah karet dan dilakukan penindakan dengan memberikan peringatan secara administratif, ${ }^{22}$ terhadap para pelanggar pencemaran lingkungan sebagai sanksi yaitu dengan mengeluarkan paksaan pemerintah, ${ }^{23}$ pembekuan izin lingkungan, pencabutan izin lingkungan dan penutupan tempat usaha. akan tetapi pengawasan secara preventif dan represif terhadap pengusaha karet ini belum terlaksana secara maksimal dan menyeluruh.

Penerapan prinsip-prinsip good governance dalam melakukan pengawasan lingkuga hidup tidak akan berjalan secara lancer jika masyarakat sendiri yang kurang perduli terhadap lingkungan hidup itu sendiri. Sedangkan Pengawasan terhadap lingkungan hidup tidak hanya hak DLH melainkan masyarakat juga memiliki peran dan hak yang sama dan seluas-luasnya untuk berperan aktif dalam perlindungan dan pengelolaan lingkungan hidup sesuai dengan Pasal 70 UU PPLH. Peran serta masyarakat dalam pengawasan pembuangan limbah karet oleh pelaku pengusaha karet ini dapat berupa pengawasan sosial, seperti pemberian usul, pendapat, saran, keberatan serta pengaduan (penyampaian informasi atau laporan) terkait kerusakan lingkungan baik akibat limbah maupun sampah.

Penggambaran model perlindungan dan pengelolaan lingkungan hidup, limbah dan sampah sesuai dengan peraturan dalam mewujudkan good governance di Kabupaten Way Kanan sebagai berikut.

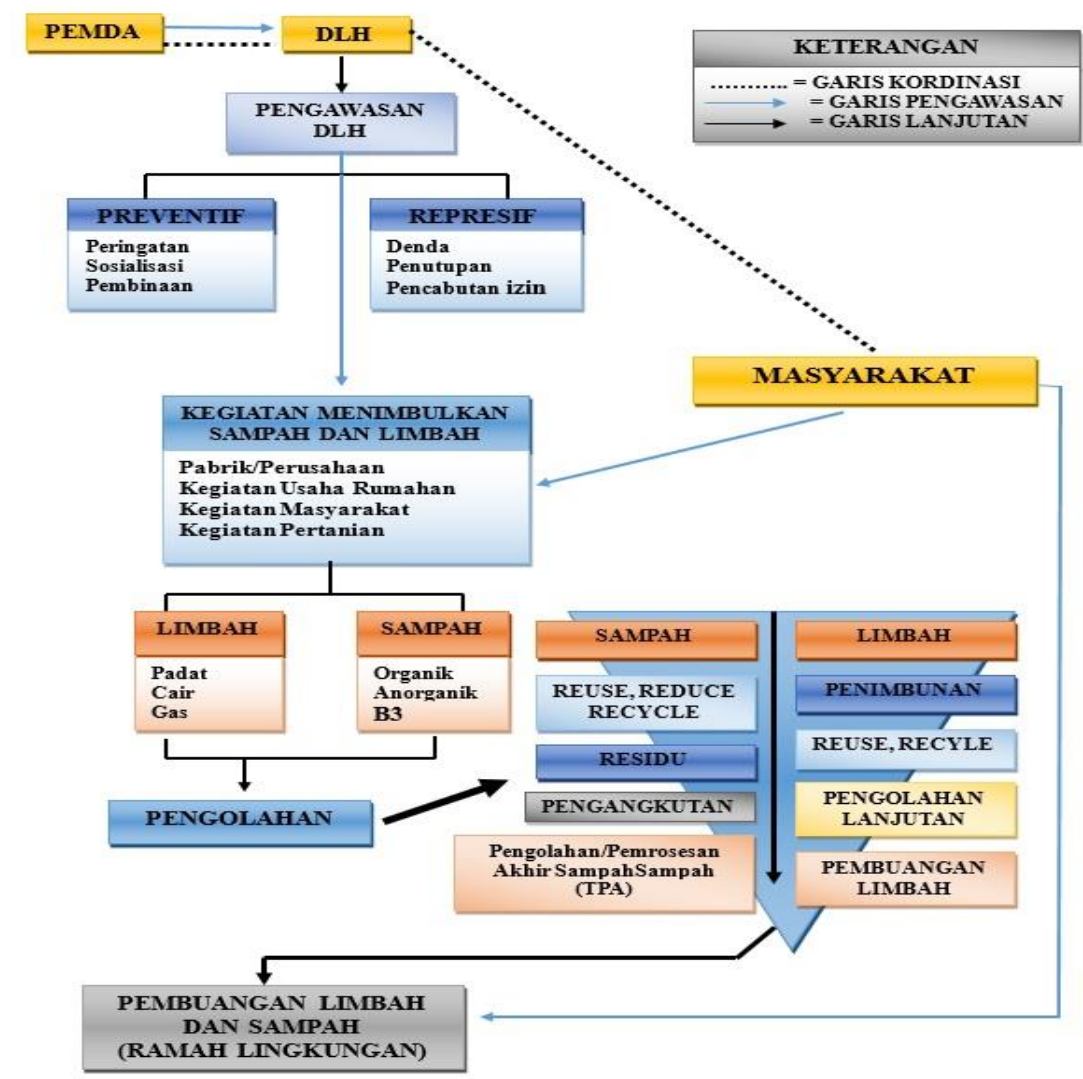

Gambar 1. Model perlindungan dan pengelolaan lingkungan hidup, limbah dan sampah.

22 Machmud, Syahrul. (2011), Penegakan Hukum Lingkungan Indonesia (Penegakan Hukum Administrasi, Hukum Perdata dan Hukum Pidana Menurut Undang-Undang No. 32 Tahun 2009, Bandung: Graha Ilmu, h. 182.

${ }^{23}$ Amiq, Bachrul. (2013), Penerapan Sanksi Administrasi dalam Hukum Lingkungan, Yogyakarta: Laksbang Mediatama, h. 27.

$$
\text { 90|SASI Vol. } 27 \text { No.1, Januari-Maret } 2021
$$




\section{P E N U T UP}

Berdasarkan hasil penelitian terkait pelaksanaan kewenangan Dinas Lingkungan Hidup dalam mengelola lingkungan hidup sebagai perwujudan Prinsip Good Governance.di Kabupaten Way Kanan, maka dapat diambil kesimpulan bahwa, pelaksanaan Kewenangan Dinas Lingkungan Hidup Kabupaten Way Kanan dalam perlindungan dang pengelolaan lingkungan hidup di Kabupaten Kanan dengan prinsip-prinsip good governance dinilai kurang optimal. Model penerapan prinsip-prinsip good governance dalam perlindungan dan pengelolaan lingkungan hidup di Kabupaten Way Kanan sudah disiapkan secara maksimal yaitu dengan penekanan pada bidang perizinan lingkungan misalnya penekanan instrumen pengawasan baik preventif dan represif akan tetapi terdapat faktor-foktor yang menjadi kendala dalam pelaksanaannya misalnya akses dan jarak serta Kurangnya peran serta masyarakat araha dan memberikan laporan serta informasi terkait prncemaran lingkungan hidup.

\section{DAFTAR PUSTAKA}

\section{Jurnal}

[1] Akib, M. (2012). Wewenang Kelembagaan Pengelolaan Lingkungan Hidup di Era Otonomi Daerah, Jurnal. Media Hukum, 19 (2), 239-250. https://journal.umy.ac.id/index.php/jmh/article/view/103.

[2] Hadjon, Philipus M. (2002 Good Governance dalam Penyelenggaraan Pemerintahan Daerah, Meritokrasi, 1 (1).

[3] Arisaputra, Muhammad Ilham. (2013), Penerapan Prinsip-Prinsip Good Governance Dalam Penyelenggaraan Reforma Agraria Di Indonesia. Yuridika, 28 (2), 188-216. http://dx.doi.org/10.20473/ydk.v28i2.1881.

[4] Muis, Muhammad Amirul Haq., Saleh, Hasrat Arief., Rusli, Andi M., (2014), Analisis Implementasi Good Governance dalam Pelayanan Publik di Kecamatan Panakukkang Kota Makassar, Government: Jurnal Ilmu Pemerintahan, 7 (2), 73-82. https://journal.unhas.ac.id/index.php/government/article/view/1246.

[5] Nopyandri. (2011), Penerapan Prinsip Good Environmental Governance dalam Perda Kabupaten Sleman Provinsi Daerah Istimewa Yogyakarta. Jurnal Ilmu Hukum, 2, (1), 3148. https://online-journal.unja.ac.id/JSSH/article/view/52.

[6] Pinilih, S. A. G. (2015). Pelaksanaan Tugas dan Wewenang Badan Lingkungan Hidup Kota Semarang Dalam Penegakan Hukum Di Bidang Lingkungan. Notarius: Jurnal Studi Kenotariatan, 8, (2), 236-251. https://doi.org/10.14710/nts.v8i2.10262 h.238.

[7] Perdana, Gema. (2019), Menjaga Netralitas ASN dari Politisasi Birokrasi. Negara Hukum: Membangun Hukum untuk Keadilan dan Kesejahteraan, 10 (1), 109-128. https://doi.org/10.22212/jnh.v10i1.1177.

[8] Rasyid, W., \& Hidayat, A. (2019), Penegakan Hukum Lingkungan Dalam Bidang Pengelolaan Sampah Sebagai Perwujudan Prinsip Good Environmental Governance di Kota Parepare. Madani Legal Review, 3 (2), 135-153. https://doi.org/10.31850/malrev.v3i2.407.

[9] Saija, V. J. E. (2014). Wewenang Pemerintah Daerah Dalam Pemberian Izin Lingkungan Hidup. SASI, 20 (1), 71-83. https://doi.org/10.47268/sasi.v20i1.347.

[10] Waas, R. V. (2014). Perlindungan Hukum Terhadap Hak Atas Lingkungan Hidup Ditinjau Dari Perspektif Hukum Internasional Dan Hukum Nasional Indonesia. SASI, 20 (1), 84-93. https://doi.org/10.47268/sasi.v20i1.348.

\section{Buku}

[11]Amiq, Bachrul. (2013), Penerapan Sanksi Administrasi dalam Hukum Lingkungan, Yogyakarta: Laksbang Mediatama. 
[12]Fajar, Mukti., \& Achmad,Yulianto. (2010), Dualisme Penelitian Hukum Normatif \& Empiris, Yogyakarta: Pustaka Pelajar.

[13] Hidayat, Arief., \& Samekto, FX Adjie. (2007), Penegakan Hukum Lingkungan di Era Otonomi Daerah, Yogyakarta, Badan Penerbit Universitas Diponegoro.

[14] Muhammad, Abdulkadir. (2004), Hukum dan penelitian Hukum, Bandung: Citra Aditya Bakti.

[15] Marzuki, Peter Mahmud. (2011), Penelitian Hukum, Jakarta: Kencana Prenada Media Group.

[16] Machmud, Syahrul. (2011), Penegakan Hukum Lingkungan Indonesia (Penegakan Hukum Administrasi, Hukum Perdata dan Hukum Pidana Menurut Undang-Undang No. 32 Tahun 2009, Bandung: Graha Ilmu.

[17] Rahmadi, Takdir. (2011), Hukum Lingkungan di Indonesia, Jakarta: Raja Grafindo Persada.

\section{Skripsi, Online/World Wide Web}

[18]Syafri, Wirman. (2011), .Dynamic Governance dan Prespektif Penyelenggaraan Pemerintah Daerah. Diakses pada www.ipdn.ac.id.

[19] Ragil, Agus Priyanto. (2011). Partisipasi Masyarakat Dalam Pengelolaan Sampah Di Kelurahan Jombang Kota Semarang (Analisis Sosio Yuridis Pasal 28 Undang Undang No 18 Tahun 2008 Tentang Pengelolaan Sampah) Skripsi: Universitas Negeri Semarang. 